Produto \& Produção, vol. 12, n. 3, p. 39-48, out. 2011

\title{
As ações de cooperação interfirmas nos arranjos produtivos locais Paranaenses
}

\author{
Rodolfo Reinaldo Petter \\ Universidade Tecnológica Federal do Paraná - UTFPR, Campus Ponta Grossa \\ rodolfo@jjcmoveis.com.br \\ Fabrício Alexandre Alves Ceranto \\ Universidade Tecnológica Federal do Paraná - UTFPR, Campus Ponta Grossa \\ fabricioceranto@hotmail.com \\ Luis Mauricio Martins de Resende \\ Universidade Tecnológica Federal do Paraná - UTFPR, Campus Ponta Grossa \\ lmresende@utfpr.edu.br
}

\section{RESUMO}

O presente artigo teve por objetivo identificar as ações de cooperação existentes entre empresas pertencentes à APLs - Arranjos Produtivos Locais, tendo como universo de pesquisa os 23 arranjos do Paraná, classificados na tipologia de arranjos produtivos locais pela Secretaria do Planejamento do Paraná e pela Federação das Indústrias do Estado do Paraná - FIEP. Assim, realizou-se uma pesquisa empírica, da qual se fundamentou na coleta de dados realizados por meio de um questionário contendo questões abertas, estando estas norteadas à identificação das ações cooperativas que se fazem presentes dentre as empresas dos APLs estudados. Este questionário foi aplicado aos administradores dos 23 APLs alocados para pesquisa, obtendo-se um retorno de 10 deles. Como resultados desta pesquisa, foram identificadas 25 ações cooperativas, das quais são caracterizadas por este trabalho como ações de cooperação interfirmas, ocorrentes especificamente na tipologia de arranjos produtivos locais.

Palavras-chave: Cooperação, Arranjos Produtivos Locais.

\begin{abstract}
This paper objective is to identify the existent cooperation actions between companies inside the APL cluster - Local Productive Arrangement, using as samples 23 clusters from Paraná State, classified inside the Local Productive Arrangement typology by the Planning Secretary of Paraná and by the Federation of Paraná State companies - FIEP. Through an empirical research supported by an application of a questionnaire, composed of open questions and related to the identification of forms of cooperation that occurs between studied APL's companies. This questionnaire was applied to the 23 APL's administrators but only 10 had answered in return. As results, there were identified 25 cooperation's, which are characterized by this work as inter-firm cooperation's, specifically occurring inside the Local Productive Arrangements typology.
\end{abstract}

Keywords: Cooperation, Local Productive Arrangements.

\section{Introdução}

Aproximadamente $60 \%$ das micro e pequenas empresas brasileiras declara falência antes de completarem cinco anos de atuação. Frente a isso, percebe-se claramente que na grande maioria dos segmentos dos quais um empreendedor deseja atuar, empresas de médio e grande porte já atuam fortemente, tendo assim o domínio sobre o segmento na região onde o micro e pequeno empreendedor deseja atuar. Desta forma, diversas empresas que estão no estágio embrionário, majoritariamente micro e pequenas - MPEs, interrompem suas atividades devido a grande dificuldade de se inserirem e atuarem em mercados dos quais suas concorrentes de grande e médio porte já dominam (SEBRAE, 2005).

Este se mostra nos últimos anos, um dos maiores desafios que MPEs vem enfrentando. Exigindo destas o desenvolvimento de estratégias que sejam capazes de potencializar seus níveis de competitividade, para que 
assim estabeleçam uma estrutura capaz de competir ao mesmo nível de abrangência mercadológica que sua concorrência de médio e grande porte atinge.

Dentre estas estratégias, a formação de arranjos produtivos locais vem se destacando nos últimos anos, por possuir a capacidade da potencialização dos níveis de competitividade das empresas que os formam, especialmente empresas de micro e pequeno porte. Esta estratégia atua na reestruturação da forma de gestão destas empresas por meio de sua organização em forma de rede de cooperação horizontal, em que todas as empresas envolvidas atuam em um mesmo segmento, tendo por objetivo principal concentrar esforços por meio de ações cooperativas para geração e potencialização de vantagens competitivas e de sustentabilidade e abrangência mercadológica.

Ainda, as micro e pequenas empresas quando organizadas neste molde de cooperação horizontal, adquirem a capacidade de aquecer a economia da região em que estão instaladas. Desta forma, começam a receber o apoio do poder público e de outras instituições alocadas na mesma região como centros de pesquisa, centros de qualificação/formação de mão de obra, etc. Esta forma de atuação conjunta, agregadas ao apoio e ao fomento de instituições públicas e privadas circunvizinhas, tem sido denominada no Brasil como Arranjos Produtivos Locais - APLs.

A atuação por meio de arranjos produtivos locais permite às MPEs que a compõe, atingir posições de mercado que estas dificilmente atingiriam trabalhando individualmente (devido à eficiência coletiva). Segundo Erber (2008), a essência do trabalho conjunto são as ações de cooperação entre empresas, pois este é o principal fator responsável pela geração da eficiência coletiva, da qual se trata do elemento-chave da potencialização da competitividade do arranjo.

Assim, pelo viés da cooperação, as MPEs brasileiras têm se estabelecido no mercado, sendo cada vez mais responsabilizadas pela geração de empregos, distribuição de renda e desenvolvimento de economias locais e regionais. Entretanto, muitas vezes a cooperação ocorre de forma ineficiente (pela qualidade com que a cooperação ocorre) e/ou insuficiente (pela baixa quantidade de ações de cooperação existentes e/ou caracterizadas), fazendo com que as MPEs pertencentes ao APL não alcancem resultados que possam caracterizar eficiência coletiva.

Ainda, esta ineficiência é alimentada pela existência de uma lacuna informacional em torno da identificação e caracterização de ações de cooperação das quais possam ser consideradas indicadores dos níveis cooperativos deste molde de atuação industrial. Para tanto, o preenchimento desta lacuna cabe não somente às governanças dos APLs, mas principalmente à academia por meio da pesquisa e desenvolvimento científico. Assim, uma das áreas mais atuantes em torno do tema redes de cooperação horizontais, como também na tipologia de arranjos produtivos locais, é a engenharia de produção. Desta forma, este trabalho possui a oportunidade de contribuir com o preenchimento desta lacuna por meio da identificação e caracterização de ações/indicadores de cooperação em arranjos produtivos locais.

No que tange ao foco desta pesquisa, esta se relaciona diretamente à governança de arranjos produtivos locais, das quais possuem dificuldades em gerenciar as relações entre as empresas que compõe o arranjo. Assim, a identificação das ações que caracterizam a cooperação interfirmas em APLs pode ser considerada um rico arcabouço de informações norteadoras das governanças no gerenciamento do arranjo produtivo, como principalmente na gestão de sua competitividade. Neste contexto, esta problemática pode ser elucidada por meio do seguinte questionamento: quais são as formas pelas quais as empresas pertencentes à APLs cooperam entre si?

O trabalho ainda apoiou-se na hipótese de que dentre as respostas provindas das governanças dos APLs estudados, é possível apontar as ações de cooperação entre as empresas destes APLs, caracterizando-se desta forma em um conjunto de ações que traduzem a cooperação interfirmas de um APL. Desta forma, esta pesquisa pode ser utilizada como uma diretriz para as governanças de APLs, dos quais almejam estimular as ações de cooperação entre as empresas da rede, fortalecendo-a assim.

Além desta parte introdutória já apresentada, o capítulo 2 faz uma breve revisão teórica em torno do escopo de arranjos produtivos locais e das ações de cooperação nestas redes. O terceiro capítulo, apresenta os procedimentos metodológicos utilizados para o desenvolvimento desta pesquisa. Por fim, o capítulo 4 apresenta os resultados obtidos, como também suas discussões.

\section{Arranjos Produtivos Locais e a Cooperação}

Um arranjo produtivo local só é caracterizado como tal, se entre seus atores exista uma intensa movimentação de informações técnicas. Esse tipo de rede possui um escopo mais amplo de gestão, expandindo-se até o tratamento de organizações, indivíduos, seus objetivos, valores e interesses (SORDI et al., 2009; CARVALHO, 2010). 
Carvalho (2010), Chennamaneni e Desiraju (2011) argumentam que um arranjo produtivo local, trata-se de um agrupamento geográfico e setorial de empresas onde haja a realização de ações conjuntas de cooperação e de economias externas (externalidades estatísticas e dinâmicas que impulsionam o crescimento econômico), gerando um ganho na eficiência coletiva para os atores participantes da rede, fomentando as vantagens competitivas e consequentemente a entrada em mercados externos, donde os atores individualmente não conseguiriam entrar.

A relevância desse tipo de estrutura encontra-se na sua capacidade de aglomerar um conjunto de variáveis como confiança, cooperação, parceria, variáveis essas responsáveis por viabilizar a permanência das empresas no mercado, bem como o desenvolvimento sustentável local (SANTOS et al., 2009). Ainda Gerolamo et al. (2008) argumenta que estas aglomerações possuem grande capacidade em desenvolver a economia de suas regiões.

O mesmo autor cita que os APLs ajudam a alavancar os indicadores econômicos e sociais de uma cidade ou região. Ao constituir toda uma cadeia produtiva, que congrega fabricantes, fornecedores de insumos, prestadores de serviço, etc., esses sistemas geram emprego e consequentemente renda. Adicionalmente, atraem instituições voltadas ao ensino profissionalizante, o que causa impacto na área da educação. Já para Trippl (2010) e Rese e Baier (2011) é evidente o papel da inovação para ampliar as oportunidades de ganhos econômicos e sociais das cidades e regiões, reforçando ainda mais a importância econômica e social que as PMEs envolvidas em clusters ou redes de cooperação têm frente ao cenário atual da necessidade de inovação e incentivo ao crescimento e desenvolvimento do país. Considerando a inovação também, como um dos caminhos da competitividade empresarial e dessa é que depende o futuro das organizações.

Entretanto, anteriormente ao APL ser constituído como um sistema de inovação, as empresas primeiramente devem formar redes regionais de inovação envolvendo cooperação estrategicamente organizada e formal estimulada pela confiança, por normas e princípios, os quais encorajam as empresas a executarem atividades de inovação (GEROLAMO et al., 2008). Neste contexto é possível perceber a relevância da cooperação entre empresas de um APL. Inicialmente na existência de cooperação entre os agentes locais da qual define a existência ou não de um APL naquela localidade; não basta apenas que haja concentração geográfica setorial, deve haver cooperação entre os membros. Além disso, a cooperação estimula a criação de um ambiente inovativo e é o meio que proporciona às empresas atingirem as vantagens competitivas que dificilmente atingiriam isoladamente, causando um efeito positivo na economia local/regional.

Segundo Souza e Cândido (2009) a razão que explica o sucesso de um APL é a existência de diversas formas de cooperação entre as empresas ou de uma mistura adequada entre competição e cooperação. Assim, o debate econômico tem se voltado fortemente para as questões da cooperação e das relações entre as firmas e os fatores que permitem ou restringem a cooperação entre firmas concorrentes.

Em estudos realizados pela Comissão Europeia - instituição politicamente independente que representa e defende os interesses da Comunidade Europeia - foi constatado que a maioria das pequenas e médias empresas (PMEs) europeias utiliza práticas de cooperação e que PMEs em redes de cooperação apresentam desempenho acima da média de sua respectiva indústria (EUROPEAN COMMISSION, 2002; EUROPEAN COMMISSION, 2004). Neste sentido, Santos et al. (2009), afirmam que a cooperação entre empresas e instituições de ensino e pesquisa é uma variável determinante da competitividade de um APL, devido sua capacidade de difundir ações inovativas.

Por outro lado, uma das dificuldades para a cooperação em APLs é a falta de confiança entre os empresários e/ ou entre os membros da cadeia produtiva em geral. Para que a cooperação ocorra, e tanto as empresas quanto a economia local sejam beneficiadas pelo trabalho conjunto, deve haver confiança entre os membros da cadeia produtiva. Para Castro, Bulgacov e Hoffmann (2011), as relações de confiança são mais facilmente geradas em ambientes de proximidade e identidade entre os agentes, o que evidencia a importância do aspecto cultural, no momento em que os agentes compartilham valores, costumes e um conjunto de regras formais ou informais, que tornam mais fácil o entendimento de quais elementos influenciam esse arranjo e quais as melhores alternativas para o desenvolvimento local.

Por fim Vasconcelos, Milagres e Nascimento (2005) argumentam que para explorar o máximo da capacidade competitiva da rede, as empresas devem ser capazes de instituir rotinas (processos) que levem à criação de uma forte identidade de rede e que possibilitem o acesso rápido e fácil dos participantes ao conhecimento tácito produzido na rede. Desta forma, todos os participantes se beneficiam não só dos resultados comuns, mas também dos resultados específicos. Uma das melhores maneiras para alcançar estes resultados, é por meio da cooperação, ou uma mistura equilibrada entre cooperação e competição. 


\section{Metodologia}

\subsection{Procedimentos metodológicos}

Para identificar as ações de cooperação que ocorrem em arranjos produtivos locais, utilizou-se como metodologia a aplicação de um questionário para a governança dos APLs paranaenses tomados como universo de pesquisa. O questionário foi aplicado via e-mail aos administradores destes arranjos e foi composto de questões abertas relacionadas à identificação das formas de cooperação que ocorrem entre as empresas constituintes destes arranjos produtivos locais. $\mathrm{O}$ questionamento principal apoiava-se na seguinte pergunta: "Quais são as formas de cooperação interfirmas que ocorrem no APL?”.

\subsection{Universo da pesquisa}

O universo desta pesquisa foram os APLs paranaenses reconhecidos pela Secretaria de Planejamento do Estado do Paraná e pela Federação das Indústrias do Estado do Paraná (FIEP), formando este um montante de 22 aglomerações produtivas, reconhecidas e registradas ainda pela Rede APL Paraná, sendo estas listadas na tabela 1 .

Ainda, de acordo com a FIEP, além dos APLs paranaenses reconhecidos pela Secretaria do Planejamento do estado, ainda existe mais um, o qual está exposto na tabela 2 .

Tabela 1 - Aglomerações paranaenses reconhecidas pela Secretaria de Planejamento do estado como arranjos produtivos locais

\begin{tabular}{|c|c|}
\hline Setor de atuação & Localidade (município ou região do estado) \\
\hline Bonés & Apucarana \\
\hline Cal e calcário & Região metropolitana de Curitiba \\
\hline Confecções & Maringá \\
\hline Confecções & Região sudoeste do estado \\
\hline Confecções infantis & Terra Roxa \\
\hline Equipamentos e implementos agrícolas & Cascavel, Toledo e Palotina \\
\hline Instrumentos médico-odonto hospitalares & Curitiba e microrregião \\
\hline Instrumentos médico-odontológicos & Campo Mourão \\
\hline Louças e porcelanas & Campo Largo \\
\hline Madeira e esquadrias & Porto União da Vitória \\
\hline Malhas & Imbituva \\
\hline Mandioca e fécula & Paranavaí \\
\hline Metais sanitários & Loanda \\
\hline Móveis & Arapongas \\
\hline Móveis & Região sudoeste do estado \\
\hline Móveis e madeira & Rio Negro \\
\hline Móveis de metal e sistemas de armazenagem e logística & Ponta Grossa \\
\hline Software & Curitiba \\
\hline $\begin{array}{l}\text { Software } \\
\text { Software }\end{array}$ & $\begin{array}{l}\text { Maringá } \\
\text { Pato Branco e Dois Vizinhos }\end{array}$ \\
\hline Tecnologia da informação & Londrina e região \\
\hline Vestuário & Cianorte \\
\hline
\end{tabular}

Fonte: Dados da pesquisa

Tabela 2 - Aglomeração paranaense reconhecida pela FIEP como arranjo produtivo local, porém ainda não identificada pela Secretaria do Planejamento do Paraná

\begin{tabular}{|l|l|}
\hline \multicolumn{1}{|c|}{ Setor de atuação } & Localidade (município ou região do estado) \\
\hline Utensílios domésticos e produtos em alumínio & Região sudoeste do estado \\
\hline
\end{tabular}


Assim, o APL Utensílios domésticos e produtos em alumínio também foi inserido na amostra pesquisada, totalizando 23 APLs. Porém, antes do envio do questionário entrou-se em contato via telefone com as governanças dos APLs, objetivando informar sobre a realização da pesquisa. O contato via telefone foi possível somente com 16 dos 23 APLs, dos quais aceitaram receber o questionário via e-mail. Destes, 10 responderam o questionário, sendo estes expostos na tabela 3 .

Tabela 3 -APLs que participaram da pesquisa

\begin{tabular}{|l|l|}
\hline \multicolumn{1}{|c|}{ Setor de atuação } & \multicolumn{1}{c|}{ Localidade (município ou região do estado) } \\
\hline Bonés & Apucarana \\
\hline Instrumentos médico-odontológicos & Campo Mourão \\
\hline $\begin{array}{l}\text { Madeira e esquadrias } \\
\text { Mandioca e fécula } \\
\text { Móveis }\end{array}$ & $\begin{array}{l}\text { Porto União da Vitória } \\
\text { Paranavaí } \\
\text { Arapongas }\end{array}$ \\
\hline $\begin{array}{l}\text { Móveis de metal e sistemas de armazenagem e logística } \\
\text { Software }\end{array}$ & Ponta Grossa \\
\hline $\begin{array}{l}\text { Tecnologia da informação } \\
\text { Utensílios domésticos e produtos em alumínio }\end{array}$ & $\begin{array}{l}\text { Condritiba e região } \\
\text { Região sudoeste do estado }\end{array}$ \\
\hline Vestuário & Cianorte \\
\hline
\end{tabular}

Fonte: Dados da pesquisa

As respostas ao questionário, por parte dos gestores dos APLs respondentes, constituíram os resultados da pesquisa, apresentados na seção 4 .

\section{Resultados e Discussão}

As respostas do questionário aplicado às governanças dos APLs estudados constituem os resultados da pesquisa. A compilação e tratamento das informações coletadas através dos questionários foram realizados em três etapas:
Etapa 1: primeiramente as respostas descritas por cada respondente foram analisadas, organizadas e expostas em sua íntegra no quadro 1 (coluna central);

Etapa 2: posteriormente, com base na etapa 1 e na análise das respostas, estas informações foram padronizadas no formato de textos genéricos, dos quais caracterizam as ações de cooperações legíveis para a governança de um APL. Esta padronização está exposta no quadro 1 (coluna à direita).

\begin{tabular}{|c|c|c|}
\hline APL & Ações de cooperação descritas pela governança & $\begin{array}{l}\text { Tradução Genérica das ações de } \\
\text { cooperação descritas }\end{array}$ \\
\hline $\begin{array}{l}\text { Bonés de } \\
\text { Apucarana }\end{array}$ & $\begin{array}{l}\text { Participação de todas das empresas fabricantes de abas plásticas utilizadas } \\
\text { nos bonés em projeto FINEP. O projeto foi concluído com sucesso, pois as } \\
\text { abas que eram fabricadas anteriormente não possuíam qualidade. }\end{array}$ & $\begin{array}{l}\text { Participação conjunta das empresas } \\
\text { em treinamento de qualificação de } \\
\text { mão de obra/produto. }\end{array}$ \\
\hline \multirow{5}{*}{$\begin{array}{l}\text { Bonés de } \\
\text { Apucarana }\end{array}$} & $\begin{array}{l}\text { Participação das empresas do APL em projeto do SENAI/SETIQ, asses- } \\
\text { sorado por consultor da Alemanha (engenheiro têxtil), visando a correta } \\
\text { formatação de modelagem de bonés. O projeto também teve completo êxi- } \\
\text { to, com a realização de capacitação em grupo de empresas e a solução do } \\
\text { problema foi através de multiplicadores. }\end{array}$ & $\begin{array}{l}\text { Participação conjunta das empresas } \\
\text { em treinamento de qualificação de } \\
\text { mão de obra/ produto. }\end{array}$ \\
\hline & Participação em missões empresariais na China (três) e Angola (uma). & $\begin{array}{l}\text { Participação conjunta das empresas } \\
\text { em missões visando formar clientela e } \\
\text { divulgar o APL no exterior. }\end{array}$ \\
\hline & $\begin{array}{l}\text { Assuntos de interesse da cadeia produtiva em reuniões empresariais, deno- } \\
\text { minadas "café com boné". }\end{array}$ & $\begin{array}{l}\text { Participação das empresas em dis- } \\
\text { cussão de assuntos ligados à cadeia } \\
\text { produtiva. }\end{array}$ \\
\hline & $\begin{array}{l}\text { Preocupação em cuidar do meio ambiente, através do projeto AMA, em } \\
\text { colaboração com a universidade sem fronteiras, FECEA, UTFPR, etc., que } \\
\text { está efetivamente tendo efeito junto à cadeia produtiva do boné. }\end{array}$ & $\begin{array}{l}\text { Participação conjunta das empresas } \\
\text { em projeto de preservação ambiental. }\end{array}$ \\
\hline & $\begin{array}{l}\text { Dois grupos de participantes da cadeia possuem sistema de compra de } \\
\text { matérias-primas em conjunto. }\end{array}$ & $\begin{array}{l}\text { Compra de matéria prima em con- } \\
\text { junto. }\end{array}$ \\
\hline
\end{tabular}


Continuação

\begin{tabular}{|c|c|c|}
\hline APL & $\begin{array}{c}\text { Ações de cooperação descritas } \\
\text { pela governança }\end{array}$ & $\begin{array}{l}\text { Tradução Genérica das ações } \\
\text { de cooperação descritas }\end{array}$ \\
\hline \multirow{3}{*}{$\begin{array}{l}\text { Instrumentos médico- } \\
\text { odontológicos de } \\
\text { Campo Mourão }\end{array}$} & Compartilhamento de informações de mercado; & $\begin{array}{l}\text { Compartilhamento de informações de mercado } \\
\text { entre as empresas }\end{array}$ \\
\hline & Participação em congressos e eventos em parceria. & $\begin{array}{l}\text { Participação conjunta das empresas em eventos } \\
\text { para divulgação do APL e formação de clientela. }\end{array}$ \\
\hline & Compartilhamento de fornecedores. & Compra de matéria prima em conjunto. \\
\hline $\begin{array}{l}\text { Madeira e esquadrias } \\
\text { de Porto União da } \\
\text { Vitória }\end{array}$ & $\begin{array}{l}\text { Participação em feiras com estandes comparti- } \\
\text { lhados. }\end{array}$ & $\begin{array}{l}\text { Participação conjunta das empresas em eventos } \\
\text { para divulgação do APL e formação de clientela. }\end{array}$ \\
\hline \multirow{7}{*}{$\begin{array}{l}\text { Madeira e esquadrias } \\
\text { de Porto União da } \\
\text { Vitória }\end{array}$} & $\begin{array}{l}\text { Rodadas de negócio em um mesmo local com inte- } \\
\text { grantes do APL e potenciais compradores de outras } \\
\text { regiões do país. }\end{array}$ & $\begin{array}{l}\text { Participação conjunta das empresas em rodadas de } \\
\text { negócios. }\end{array}$ \\
\hline & $\begin{array}{l}\text { Missões internacionais visitando feiras na Europa } \\
\text { e América do Sul em busca de novas tecnologias e } \\
\text { prospecção de mercado. }\end{array}$ & $\begin{array}{l}\text { Participação conjunta das empresas em missões } \\
\text { visando formar clientela e divulgar o APL no exte- } \\
\text { rior. }\end{array}$ \\
\hline & Lobby junto a órgãos públicos em defesa do setor. & $\begin{array}{l}\text { Participação das empresas em discussão de assun- } \\
\text { tos ligados à cadeia produtiva. }\end{array}$ \\
\hline & Emissão de material promocional conjunto. & Marketing conjunto realizado pelas empresas. \\
\hline & $\begin{array}{l}\text { Site institucional de divulgação e venda de produ- } \\
\text { tos. }\end{array}$ & $\begin{array}{l}\text { Marketing conjunto realizado pelas empresas } \\
\text { Venda conjunta de produtos conjunta via internet. }\end{array}$ \\
\hline & $\begin{array}{l}\text { Busca de recursos e apoio técnico para criação de } \\
\text { laboratório de teste de produtos. }\end{array}$ & $\begin{array}{l}\text { Investimento conjunto em pesquisa e desenvolvi- } \\
\text { mento para melhoria de produtos. }\end{array}$ \\
\hline & Treinamentos para qualificação de mão de obra. & $\begin{array}{l}\text { Participação conjunta das empresas em treinamen- } \\
\text { to de qualificação de mão de obra. }\end{array}$ \\
\hline \multirow{3}{*}{$\begin{array}{c}\text { Mandioca e fécula de } \\
\text { Paranavaí }\end{array}$} & $\begin{array}{l}\text { Compartilhamento de informações de mercado. As } \\
\text { empresas de fécula mantém convênio com o CE- } \\
\text { PEA que trabalha com o levantamento de preços } \\
\text { da matéria prima. }\end{array}$ & $\begin{array}{l}\text { Compartilhamento de informações de mercado } \\
\text { entre as empresas. }\end{array}$ \\
\hline & Busca de tecnologia. & Busca conjunta de tecnologia. \\
\hline & Busca de desenvolvimento de novos produtos. & $\begin{array}{l}\text { Busca conjunta do desenvolvimento de novos pro- } \\
\text { dutos. }\end{array}$ \\
\hline \multirow{5}{*}{ Móveis de Arapongas } & Participação em feiras e exposições. & $\begin{array}{l}\text { Participação conjunta das empresas em eventos } \\
\text { para divulgação do APL e formação de clientela. }\end{array}$ \\
\hline & Missões internacionais. & $\begin{array}{l}\text { Participação conjunta das empresas em missões } \\
\text { visando formar clientela e divulgar o APL no exte- } \\
\text { rior. }\end{array}$ \\
\hline & Treinamento de funcionários; & $\begin{array}{l}\text { Participação conjunta das empresas em treinamento } \\
\text { de qualificação de mão de obra. }\end{array}$ \\
\hline & Acesso a linhas de crédito. & Obtenção conjunta de linhas de crédito. \\
\hline & Apoio institucional do SEBRAE e FIEP. & $\begin{array}{l}\text { Trabalho conjunto das empresas com órgãos pú- } \\
\text { blicos. }\end{array}$ \\
\hline \multirow{2}{*}{$\begin{array}{l}\text { Móveis de metal e } \\
\text { sistemas de armaze- } \\
\text { nagem e logística de } \\
\text { Ponta Grossa }\end{array}$} & Treinamento de pessoal em conjunto. & $\begin{array}{l}\text { Participação conjunta das empresas em treinamen- } \\
\text { tos para qualificação de mão de obra. }\end{array}$ \\
\hline & Participação conjunta em feiras. & $\begin{array}{l}\text { Participação conjunta das empresas em eventos } \\
\text { para divulgação do APL e formação de clientela. }\end{array}$ \\
\hline
\end{tabular}


Continuação

\begin{tabular}{|c|c|c|}
\hline APL & $\begin{array}{l}\text { Ações de cooperação descritas } \\
\text { pela governança }\end{array}$ & $\begin{array}{l}\text { Tradução Genérica das ações } \\
\text { de cooperação descritas }\end{array}$ \\
\hline \multirow{5}{*}{ Software de Curitiba } & $\begin{array}{l}\text { Contratação de consultoria e treinamento para capa- } \\
\text { citação, tanto na área técnica quanto nas áreas de } \\
\text { marketing e vendas. }\end{array}$ & $\begin{array}{l}\text { Contratação conjunta de consultoria para aperfei- } \\
\text { çoamento de áreas críticas para a sobrevivência da } \\
\text { rede. }\end{array}$ \\
\hline & Contratação de assessoria de imprensa. & Contratação conjunta de assessoria de empresa. \\
\hline & $\begin{array}{l}\text { Compra conjunta de pacotes para participação em } \\
\text { eventos. }\end{array}$ & $\begin{array}{l}\text { Participação conjunta das empresas em eventos } \\
\text { para divulgação do APL e formação de clientela. }\end{array}$ \\
\hline & Preparação das empresas para internacionalização. & $\begin{array}{l}\text { Preparação conjunta das empresas para atuar no } \\
\text { mercado externo }\end{array}$ \\
\hline & Discussão de temas de interesse comum. & $\begin{array}{l}\text { Participação conjunta das empresas em discussões } \\
\text { de assuntos ligados a cadeia produtiva. }\end{array}$ \\
\hline \multirow{5}{*}{$\begin{array}{l}\text { Tecnologia da } \\
\text { informação } \\
\text { de Londrina } \\
\text { e região }\end{array}$} & \multirow{3}{*}{$\begin{array}{l}\text { Em relação ao processo de compra, o nosso APL } \\
\text { fundou a primeira Central de Negócios de TI do } \\
\text { Brasil (CINTEC). A primeira ação estruturante é } \\
\text { a de compras conjuntas e nos passos seguintes } \\
\text { estaremos focando vendas e demais atividades das } \\
\text { empresas em conjunto também. }\end{array}$} & Formação conjunta de uma central de negócios. \\
\hline & & Compra conjunta de matéria prima. \\
\hline & & Venda conjunta de produtos. \\
\hline & \multirow{2}{*}{$\begin{array}{l}\text { No tocante ao compartilhamento de informações, } \\
\text { os APLs estão estruturados numa rede APL do } \\
\text { estado, onde existe a troca de informações sobre } \\
\text { as boas práticas adotadas em cada APL. Fora isso, } \\
\text { com a possibilidade de networking nestes encon- } \\
\text { tros, também é realizada troca de experiências } \\
\text { entre empresas. Ainda neste sentido as reuniões } \\
\text { semanais que são feito no nosso APL também pos- } \\
\text { sibilita essa troca de informações. }\end{array}$} & $\begin{array}{l}\text { Troca de informações das empresas com os demais } \\
\text { APLs, referentes às boas práticas de cooperação. }\end{array}$ \\
\hline & & $\begin{array}{l}\text { Compartilhamento de informações entre as em- } \\
\text { presas. }\end{array}$ \\
\hline \multirow{9}{*}{$\begin{array}{l}\text { Utensílios domésticos } \\
\text { e produtos em } \\
\text { alumínio da região } \\
\text { sudoeste do estado }\end{array}$} & \multirow{2}{*}{$\begin{array}{l}\text { Periodicamente fazemos reuniões e contratamos } \\
\text { consultores a fim de diagnosticar quais as princi- } \\
\text { pais deficiências entre as empresas participantes e } \\
\text { a partir daí são feitas as diretrizes de trabalho. }\end{array}$} & $\begin{array}{l}\text { Contratação conjunta de consultoria para aperfei- } \\
\text { çoamento de áreas críticas para a sobrevivência da } \\
\text { rede. }\end{array}$ \\
\hline & & $\begin{array}{l}\text { Estudo conjunto das empresas para a implantação } \\
\text { de melhorias. }\end{array}$ \\
\hline & $\begin{array}{l}\text { Visitas técnicas tanto em feiras do setor metal me- } \\
\text { cânico, ou feiras voltadas ao segmento de utensí- } \\
\text { lios domésticos. }\end{array}$ & $\begin{array}{l}\text { Participação conjunta das empresas em visitas em } \\
\text { feiras do setor. }\end{array}$ \\
\hline & $\begin{array}{l}\text { Trocas de informações com outros polos de pro- } \\
\text { dução de alumínio (SENAI Itaúna) foram feitas } \\
\text { trocas de visitas entre os dois polos. }\end{array}$ & $\begin{array}{l}\text { Troca de informações técnicas entre empresas e } \\
\text { agentes externos que possuem conhecimento no } \\
\text { setor de atuação das empresas. }\end{array}$ \\
\hline & \multirow{2}{*}{$\begin{array}{l}\text { Treinamentos voltados às empresas do setor } \\
\text { (marketing, vendas, planejamento estratégico, } \\
\text { segurança no trabalho, formação de lideranças.) } \\
\text { todos os treinamentos parte são subsidiados pelos } \\
\text { parceiros do APL (SINDIMETAL SUDOESTE, } \\
\text { SEBRAE, SESI, SENAI, prefeitura de Pato Bran- } \\
\text { co, prefeitura de Francisco Beltrão, CACISPAR, } \\
\text { Agência Sudoeste, UTFPR campus Pato Branco, } \\
\text { Colégio Mater Dei, Fadep) e parte os empresários } \\
\text { investem. }\end{array}$} & $\begin{array}{l}\text { Participação conjunta das empresas em treinamen- } \\
\text { tos para qualificação administrativa }\end{array}$ \\
\hline & & $\begin{array}{l}\text { Fomento financeiro às empresas por parte de ór- } \\
\text { gãos públicos/associações de classe. }\end{array}$ \\
\hline & $\begin{array}{l}\text { As trocas de informações entre os empresários são } \\
\text { feita nas reuniões onde também com o passar do } \\
\text { tempo quebra-se as barreiras de desconfiança e se } \\
\text { tem maior liberdade e confiança nos parceiros. }\end{array}$ & $\begin{array}{l}\text { Participação conjunta das empresas em discussões } \\
\text { de assuntos ligados a cadeia produtiva. }\end{array}$ \\
\hline & \multirow{2}{*}{$\begin{array}{l}\text { Conseguimos junto com um dos parceiros o SENAI } \\
\text { comprar equipamentos a fim de realizarmos cursos } \\
\text { para formação de mão de obra; o curso é realizado } \\
\text { durante o ano e várias vezes já foi subsidiado total- } \\
\text { mente pela prefeitura de Francisco Beltrão. }\end{array}$} & $\begin{array}{l}\text { Participação conjunta das empresas em projeto/ } \\
\text { treinamento de qualificação de mão de obra. }\end{array}$ \\
\hline & & $\begin{array}{l}\text { Fomento financeiro às empresas por parte de ór- } \\
\text { gãos públicos/associações de classe. }\end{array}$ \\
\hline
\end{tabular}


Continuação

\begin{tabular}{|c|c|c|}
\hline APL & $\begin{array}{l}\text { Ações de cooperação descritas } \\
\text { pela governança }\end{array}$ & $\begin{array}{l}\text { Tradução Genérica das ações } \\
\text { de cooperação descritas }\end{array}$ \\
\hline \multirow{2}{*}{$\begin{array}{l}\text { Utensílios domésticos } \\
\text { e produtos em alumí- } \\
\text { nio da região sudoes- } \\
\quad \text { te do estado }\end{array}$} & $\begin{array}{l}\text { Estamos iniciando um projeto para futuramente } \\
\text { implantarmos uma central de negócios. }\end{array}$ & $\begin{array}{l}\text { Estudo conjunto das empresas para a implantação } \\
\text { de melhorias. }\end{array}$ \\
\hline & $\begin{array}{l}\text { Estamos desenvolvendo um equipamento em parce- } \\
\text { ria com o SENAI afim de automatizar um processo } \\
\text { critico de produção das empresas. }\end{array}$ & $\begin{array}{l}\text { Parceria conjunta das empresas com instituições } \\
\text { de desenvolvimento de tecnologia. }\end{array}$ \\
\hline \multirow[t]{2}{*}{ Vestuário de Cianorte } & Treinamentos. & $\begin{array}{l}\text { Participação conjunta das empresas em projetos/ } \\
\text { atividades para qualificação da mão de obra/pro- } \\
\text { duto. }\end{array}$ \\
\hline & $\begin{array}{l}\text { Reuniões Setoriais para troca de experiências (Ex. } \\
\text { Setor Lavanderias, Estamparia). }\end{array}$ & $\begin{array}{l}\text { Participação conjunta das empresas em discussões } \\
\text { de assuntos ligados a cadeia produtiva. }\end{array}$ \\
\hline
\end{tabular}

Quadro 1 - Respostas das governanças dos 10 APLs participantes da pesquisa e suas respectivas traduções genéricas Fonte: Dados da pesquisa

No quadro 1 é possível observar que uma das ações de cooperação que mais ocorrem é a compra conjunta de matéria prima. Segundo o responsável pela governança do setor metal mecânico de Ponta Grossa, a compra de matéria-prima em conjunto (maior volume de compra), possibilita a obtenção de melhores preços pela unidade da matéria-prima necessária, além de melhores condições de prazos para pagamento. Assim, este é um fator que possibilita as empresas repassarem um produto com menor preço no mercado, tornando-se mais competitiva no item preço final do produto.

Ainda, foi possível realizar alguns outros levantamentos acerca dos APLs estudados. Segundo o responsável pela governança do APL de móveis e madeira de Rio Negro, o APL não existe mais, motivo pelo qual ele não respondeu o questionário. Segundo o gestor, o motivo do declínio do APL foi a falta de comprometimento das empresas com as questões ligadas a cooperação. $\mathrm{O}$ gestor ainda argumentou que a situação chegou a este ponto devido a disparidade muito grande entre os portes das empresas, as quais se dividiam nitidamente em dois grupos: as madeireiras de maior, que produziam em maior escala; e os pequenos empresários, normalmente marcenarias. $\mathrm{O}$ administrador do antigo APL concluiu as grandes empresas certamente não viam vantagens em trabalhar em conjunto com os pequenos.

Desta forma, partindo da compilação de dados e constatações expostas na etapa 2, a etapa 3 que segue listou as ações e/ou indicadores de cooperação identificados no tratamento de informações coletadas.

Etapa 3: nesta etapa construiu-se a listagem (tabela 4) das ações de cooperação consideradas genéricas para os APLs estudados, sendo estas ações não somente para os APLs pesquisados, consideradas indicadores de cooperação interfirmas independentemente da estrutura organizacional do arranjo. Ou seja, propôsse e realizou-se a tradução genérica das respostas dos respondentes como um viés para reduzir ao máximo as características específicas das ações de cooperação dos arranjos pesquisados, para que estas informações então pudessem ser consideradas indicadores genéricos de cooperação interfirmas em arranjos produtivos locais.

Tabela 4 - Ações de cooperação entre empresas pertencentes aos arranjos produtivos locais paranaenses

\section{Ações de cooperação detectadas entre as empresas pertencentes aos arranjos produtivos locais paranaenses}

Busca conjunta do desenvolvimento de novos produtos

Busca conjunta de tecnologia

Compartilhamento de informações de mercado entre empresas

Compra de matéria prima em conjunto

Contratação conjunta de assessoria de imprensa

Contratação conjunta de consultoria para aperfeiçoamento de áreas críticas para a sobrevivência da rede

Estudo conjunto das empresas para a implementação de melhorias

Formação conjunta de uma central de negócios

Investimento conjunto em pesquisa e desenvolvimento para melhoria de produtos

Marketing conjunto realizado pelas empresas

Obtenção conjunta de linhas de crédito

Parceria conjunta das empresas com instituições de desenvolvimento de tecnologia 
Continuação

25 Ações de cooperação detectadas entre as empresas pertencentes aos arranjos produtivos locais paranaenses

Participação conjunta das empresas em eventos para divulgação do APL e formação de clientela

Participação conjunta das empresas em missões visando formar clientela e divulgar o APL no exterior

Participação conjunta das empresas em projeto de preservação ambiental

Participação conjunta das empresas em rodadas de negócios

Participação conjunta das empresas em visitas em feiras do setor

Participação conjunta das empresas em treinamento de qualificação de mão de obra/ produto

Participação conjunta das empresas em treinamentos para qualificação administrativa

Participação das empresas em discussão de assuntos ligados à cadeia produtiva

Preparação conjunta das empresas para atuar no mercado externo

Trabalho conjunto das empresas com órgãos públicos

Troca de informações das empresas com os demais APLs, referentes às boas práticas de cooperação

Venda conjunta de produtos

Venda conjunta de produtos conjunta via internet

Fonte: Dados da pesquisa

Ainda, a formação da tabela 2 teve por objetivo abranger o máximo de detalhes de informações referente às ações de cooperação descritas nas respostas dos governantes, porém simplificando-as em termos genéricos e estruturados, de modo que respostas de APLs diferentes que se referem à mesma forma de cooperação sejam traduzidas da mesma maneira. Assim, as ações listadas pela tabela 2 constituem o principal resultado da presente pesquisa.

Estas ações, em seu formato de indicadores e diretrizes, tem a opção de serem utilizadas como diretrizes para o fomento e criação das interações cooperativas entre empresas de um APL por sua governança, tendo por objetivo macro alimentar o desenvolvimento evolutivo competitivo do arranjo por meio da cooperação interfirmas.

\section{Considerações Finais}

Este artigo teve por objetivo principal identificar as formas pelas quais empresas participantes de APLs cooperam entre si por meio da aplicação de um questionário aos administradores das governanças de 10 APLs atuantes e formalizados nos estado do Paraná. Assim, fundamentado na hipótese de que o apontamento destas ações é possível por meio da indagação a esses administradores, a presente pesquisa obteve como resultado em resposta a essa hipótese e problemática, 25 apontamentos e/ou ações das quais são caracterizadas como sendo ações de cooperação interfirmas ocorrentes entre as empresas dos APLs estudados.

Partindo das declarações descritas pelos administradores dos APLs respondentes da pesquisa, foi possível realizar a filtragem destas e construir uma grade de "ações padrão" de cooperação interfirmas comuns aos 10 APLs estudados por esta pesquisa. Porém, com base nesta constatação afirma-se que os APLs estudados ainda apresentaram em média um baixo número de ações de cooperação. De acordo com a fundamentação teórica exposta por esta pesquisa na seção 2, APLs são ambientes que permitem e exigem um nível de integração e de execução de ações cooperativas muito grandes, sendo este vinculado à quantidade de ações de cooperação efetuadas pelas empresas constituintes de um APL, onde o montante destas ações em um APL considerado de com um bom nível cooperativo é maior do que o montante detectado nos 10 APLs paranaenses pesquisados.

Além da baixa quantidade das ações de cooperação existentes, também se deve observar a qualidade destas ou a capacidade destas de trazer retornos positivos para as empresas e economia local/regional. Esta observação pode ser feita em termos do grau de inovação das ações cooperativas. Observou-se que, conforme predito pela fundamentação teórica da seção 2 (QUANDT, 2004), as ações de caráter inovativo realmente são escassas. Assim, destaca-se às governanças dos APLs estudados e dos demais APLs distribuídos ao longo do território paranaense e nacional, para um maior investimento em ações de cooperação de maneira mais organizada e formal, estimulada pela confiança, por normas e princípios que encorajem as empresas a executarem atividades de inovação, conforme comenta Gerolamo et al. (2008).

Desta maneira acredita-se que, os ganhos econômicos e sociais das empresas e regiões podem ser acentuados, evidenciando a importância econômica e social que as MPEs envolvidas em redes de cooperação exercem frente ao cenário atual de necessidade de inovação e incentivo ao crescimento e desenvolvimento do país. 


\section{Referências}

CARVALHO, M. M.; LAUTINDO, F. J. B. Estratégia Competitiva: dos conceitos à implementação. $2^{\mathrm{a}}$ ed., São Paulo: Atlas, 2010.

CASTRO, M.; BULGACOV, S.; HOFFMANN, V. E. Relacionamentos Interorganizacionais e Resultados: Estudo em uma Rede de Cooperação Horizontal da Região Central do Paraná. Revista de Administração Contemporânea - RAC. v. 15, n. 1, p. 25-46, 2011.

CHENNAMANENI, P. R.; DESIRAJU, R. Comarketing Alliances: Should You Contract on Actions or Outcomes? Management Science. v. 57, n. 4, p. 752-762, 2011.

ERBER, F. S. Eficiência coletiva em arranjos produtivos locais industriais: comentando o conceito. Revista Nova Economia. Belo Horizonte, v. 18, n. 1, p. 11-31, 2008.

EUROPEAN COMMISSION. Observatory of European SMEs 2002, n. 3 - Regional clusters in Europe. Report submitted to the Enterprise Directorate General by KPMG Special Services, EIMB Business \& Policy Research and ENSR. Luxembourg: Office for Official Publications of the European Communities, 2002.

EUROPEAN COMMISSION. Observatory of European SMEs 2003, n. 5 - SMEs and cooperation. 2004. Disponível em: <http://ec.europa.eu/enterprise/enterprise_policy/analysis/observatory _en.htm>. Acesso em 17 de mar. 2011.

GEROLAMO, M. C.; CARPINETTI, L. C. R.; FLESCGUTZ, G. S.; SELIGER, G. Clusters e redes de cooperação de pequenas e médias empresas: observatório europeu, caso alemão e contribuições ao caso brasileiro. Revista Gestão \& Produção, São Carlos, v. 15, n. 2, p. 351-365, maio-ago., 2008.

QUANDT, C. O. Inovação em Clusters Emergentes. Consciência: Revista Eletrônica de Jornalismo Científico - Desafios da Inovação, n. 57, p. 1-5. ago. 2004. Disponível em: <http://www.comciencia.br/reportagens/2004/08/13.shtml>. Acesso em: 8 de mar. 2011.
RESE, A.; BAIER, D. Success factors for innovation management in networks of small and medium enterprises. R\&D Management. v. 41, n. 2, 2011.

SANTOS, J. A.; COSTA, I.; AMORIM, B. P.; CÂNDIDO, G. A. Competitividade em arranjos produtivos locais: uma análise do arranjo produtivo local de software de João Pessoa - PB. Revista Gestão Industrial, v. 5, n. 4, p. 42-58, 2009.

SEBRAE. Boletim estatístico de Micro e Pequenas empresas. Observatório SEBRAE. $1^{\circ}$ semestre de 2005.

SECRETARIA DO ESTADO DO PLANEJAMENTO DO ESTADO DO PARANÁ. Rede APL Paraná. Disponível em <http://www.redeapl.pr.gov.br>. Acesso em 10 mar. 2011.

SORDI, J. O. et al. Competências críticas ao desenvolvimento de mapas cognitivos de redes de cooperação horizontal de micro e pequenas empresas. Revista de Administração Pública - RAP. v. 43, n. 5, p. 11811206, 2009.

SOUZA, S. M. A.; CÂNDIDO, G. A. Relações entre as formas de governança de arranjos produtivos com a competitividade e o desenvolvimento local sustentável. Revista Gestão Industrial, Ponta Grossa, v. 5, n. 1, p. 161-187, 2009.

TRIPPL, M. Developing Cross-Border Regional Innovation Systems: Key Factors and Challenges. Tijdschrift voor Economische en Sociale Geografie. v. 101, n. 2, p. 150-160, 2010.

VASCONCELOS, M. C. R. L.; MILAGRES, R.; NASCIMENTO, E. Estratégia de relacionamento entre os membros da cadeia produtiva no brasil: reflexões sobre o tema. Revista Gestão \& Produção, São Carlos, v. 12, n. 3, p. 393-404, set.-dez., 2005.

Recebido em: 19/05/2011. Aceito em: 15/08/2011. 